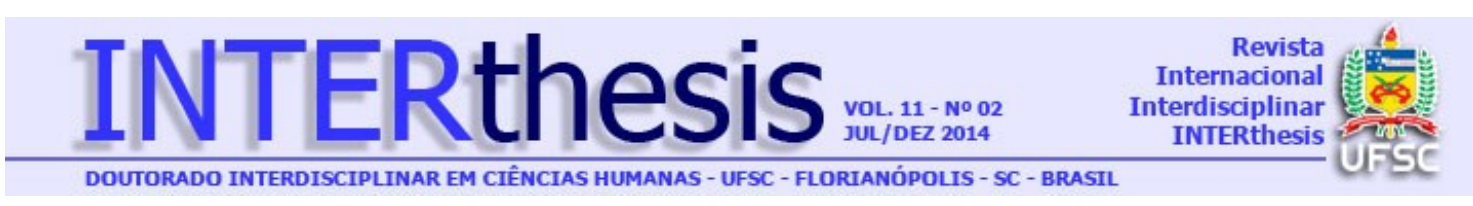

\title{
FILOSOFIA INTERCULTURAL E PARADIGMA EMERGENTE: UM NOVO ENFOQUE PARA AS “RAZÕES” DE UMA CULTURA DIFERENTE
}

\section{Resumo}

\author{
Ana Marcia Kaliberda ${ }^{1}$ \\ Cesar Rey Xavier ${ }^{2}$ \\ Carlos Alberto Marçal Gonzaga ${ }^{3}$
}

Inicia-se este trabalho com uma problematização de certa crise paradigmática que, de acordo com alguns autores, não se restringe ao módus faciendi científico, atingindo também o próprio conhecimento, considerado este sob uma perspectiva mais ampla, aplicando-se a todo o conjunto de nossos valores e relações entre homem, natureza e sociedade. Cabe salientar a crise do que se nomeia como "paradigma dominante", através da qual urge a necessidade de um novo fazer científico e uma nova forma de apropriação do conhecimento, em que o senso comum é resgatado e recebe a devida valoração. Esta é a proposta do assim chamado "paradigma emergente" que, segundo entendemos, prepara o caminho para que a heterodoxia de propostas como a da Filosofia Intercultural encontrem solo propício na construção de formas alternativas para se encarar culturas e saberes autóctones. Descrevem-se alguns aspectos epistemológicos que compõem a Filosofia Intercultural, em especial a sua negativa com respeito ao etnocentrismo. Pretende-se argumentar que esta nova forma de filosofar atende aos requisitos de um paradigma emergente, na medida em que não privilegia este ou aquele logos como a "razão absoluta e universal", mas permite a expressão de outras formas de racionalidade que, não raro, chocam os padrões do que se considera "convencional", como é o caso das culturas indígenas. O conjunto destes princípios paradigmáticos e interculturais encontra eco na interpretação de algumas formas de racionalidade típicas da Reserva Indígena Rio D' Areia, situada no município de Inácio Martins, no Paraná, cuja coleta de dados foi realizada através da observação participante.

Palavras-chave: Paradigma. Racionalidade. Etnocentrismo. Filosofia intercultural. Comunidade indígena.

\footnotetext{
1 Mestranda em Desenvolvimento Comunitário pela Universidade Estadual do Centro Oeste, Guarapuava, PR. Graduação em Pedagogia pela Universidade Estadual do Centro-Oeste (2006). Professora da Associação Pais e Amigos dos Excepcionais em Irati, Irati, PR, Brasil. E-mail: anamkaliberda@gmail.com

2 Doutor em Filosofia da Mente pela Universidade Federal de São Carlos. Professor Adjunto na Universidade Estadual do Centro Oeste, Guarapuava, PR, Brasil. E-mail: reyxavier@gmail.com

3 Doutor em Engenharia Florestal pela Universidade Federal do Paraná. Professor Adjunto da Universidade Estadual do Centro-Oeste, Guarapuava, PR, Brasil. E-mail: admgonzaga@yahoo.com.br
}

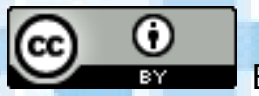

Esta obra foi licenciada com uma Licença Creative Commons - Atribuição 3.0 Não Adaptada. 


\section{INTRODUÇÃO}

O objetivo mais abrangente deste trabalho é analisar as possibilidades de convivência harmônica entre diferentes culturas, à luz da filosofia intercultural, a qual considera o lugar, a cultura, o momento histórico, dentre outros fatores, e em especial o "logos"4 intrínseco a cada etnia, povo e cultura. Na esteira desta forma inovadora de filosofia é possível também deslindar alguns sinais que apontam para certa urgência de um "paradigma emergente" que dê conta de abarcar variáveis e aspectos sociais e humanos até então carentes de atenção sob a ótica do que alguns autores chamam de "paradigma dominante". Entende-se que a filosofia intercultural atenda aos requisitos de um paradigma emergente, capaz então de compreender empaticamente as saliências culturais de povos cuja racionalidade e simbolizações contrastem sobremaneira com o nosso modo próprio e habitual de se pensar o cotidiano. A investigação concentrou-se em coletar dados da Reserva Indígena Rio D' Areia, localizada no interior do Município de Inácio Martins, composta por 23 famílias, totalizando em média 100 índios, com predominância da etnia Guarani. Há também na aldeia uma índia da etnia Xetá, a qual é casada com um índio paraguaio, recebendo influências dos costumes Guaranis.

Trata-se de uma pesquisa qualitativa, na qual são confrontadas algumas noções conceituais pertinentes à revisão bibliográfica consultada. Adjacentes a estas fontes, apresentam-se alguns dados e impressões que foram coletados mediante a técnica de observação participante. "A pesquisa participante consiste na inserção do pesquisador no ambiente natural de ocorrência do fenômeno e de sua interação com a situação investigada." (PERUZZO, 2003, p.2). Desta forma, para se obter um bom resultado nas observações foram realizadas conversas informais com pessoas da comunidade indígena. Assim, essa metodologia é considerada apropriada para colher todo um conjunto de impressões das relações dos sujeitos investigados que normalmente escapam de outras formas de observação. Há que se adiantar, contudo, que tais impressões servirão apenas como ilustração de formas diferentes de racionalidade, em comparação com a nossa.

\footnotetext{
${ }^{4}$ Daqui por diante, estaremos empregando este vocábulo latino com a sinonímia de "racionalidade".
}

R. Inter. Interdisc. INTERthesis, Florianópolis, v.11, n.2, p.37-54, Jul-Dez. 2014
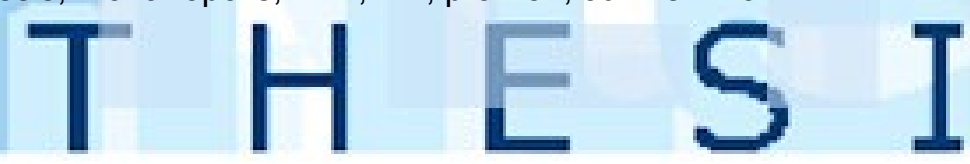


\section{A CRISE DO PARADIGMA DOMINANTE}

Seria leviano adentrar uma análise que empregue este conceito sem reaver as noções básicas que o circunscrevem através de seu principal mentor. Segundo T. S. Kuhn (1978), paradigma diz respeito a um conjunto de critérios para desenvolver pesquisa. Sem paradigma não é possível fazer ciência, levantar hipótese, buscar saídas, portanto são: "realizações científicas universalmente reconhecidas que, durante algum tempo, fornecem problemas e soluções modelares para uma comunidade de praticantes de uma ciência" (KUHN, 1978, p. 20). Ainda que estas noções acerca de um "padrão de conduta" das diversas comunidades científicas possam soar de forma um tanto "vaga", podem, não obstante, ajudar na boa compreensão dos modos de se conceber o conhecimento em dada época. Tal compreensão, por sua vez, pode fornecer um quadro das tendências e valores epistêmicos que norteiam a época em questão, os quais inevitavelmente influenciam os modos de interpretar a natureza, as sociedades, as culturas e a própria racionalidade. Pela ótica de alguns pensadores, estamos assistindo uma transição paradigmática que nos desvela a urgente necessidade de revisarmos certos valores de conduta e interpretação das coisas de nosso conhecimento de homem, de natureza e da própria ciência.

A ciência moderna construiu-se contra o senso comum que considerou superficial. "A ciência moderna produz conhecimentos e desconhecimentos. Se faz do cientista um ignorante especializado faz do cidadão comum um ignorante generalizado" (SANTOS, B. 2008, p. 88). O autor salienta que o senso comum foi deixado de lado como conhecimento. Existe a necessidade de nos livrarmos de amarrações do passado, ligando o saber científico com o empírico. Assim,

\footnotetext{
Estamos de novo regressados à necessidade de perguntar pelas relações entre a ciência e a virtude, pelo valor do conhecimento dito ordinário ou vulgar que nós, sujeitos individuais ou coletivos, criamos e usamos para dar sentido às nossas práticas e que a ciência teima em considerar irrelevante, ilusório e falso. (SANTOS, B.S. 2008, p. 18)
}

Santos (2008) descreve a crise do paradigma dominante. A ciência moderna não está dando conta de responder os acontecimentos sociais, a estrutura científica resultou no conhecimento e seu aprofundamento levou à descoberta de sua fragilidade. "A ideia de que não conhecemos do real senão o que nele introduzimos."

R. Inter. Interdisc. INTERthesis, Florianópolis, v.11, n.2, p.37-54, Jul-Dez. 2014
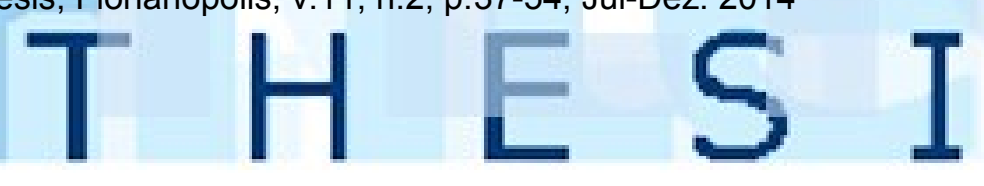
(SANTOS, B. 2008, p. 44). Essas condições nos levam a uma reflexão epistemológica sobre o conhecimento científico para dar subsídios na formulação do nossa proposta. Os cientistas atuais tendem a se utilizar de conhecimentos filosóficos para problematizar sua prática científica. É certo que o conhecimento do senso comum tende a ser burlado, mas apesar disso, tem uma dimensão utópica e libertadora que pode ser ampliada através do diálogo com o conhecimento científico. Afirma o autor:

Depois da euforia cientista do século XIX e da consequente aversão à reflexão filosófica, bem simbolizada pelo positivismo, chegámos a finais do século $\mathrm{XX}$ possuídos pelo desejo quase desesperado de complementarmos o conhecimento das coisas com o conhecimento do conhecimento das coisas, isto é, com o conhecimento de nós próprios. (SANTOS, B. 2008, p. 50).

A crise do paradigma da ciência moderna se deu por várias condições, tanto teóricas quanto sociais. A industrialização das ciências acarretou um compromisso com os centros de poder econômico, social e político. "A caracterização da crise do paradigma dominante traz consigo o perfil do paradigma emergente" (SANTOS, B. 2008, p. 58-59). No paradigma emergente o conhecimento é total, sem deixar de lado sua característica local, como exemplo nos temas aplicados a grupos sociais, como projetos de vida local.

A interação do ser humano contribui para a construção do conhecimento e dos valores individuais e coletivos, promovendo os preceitos culturais, econômicos e socioambientais. "A ciência pós-moderna procura reabilitar o senso comum por reconhecer nesta forma de conhecimento algumas virtualidades para enriquecer a nossa relação com o mundo" (SANTOS, B. 2008, p. 88-89). Como bem assevera B. Santos (2008), o senso comum tem o princípio de igualdade do acesso ao discurso, portanto, não resulta de uma prática especificamente orientada para produzir, mas se reproduz espontaneamente no dia-a-dia. Está claro que não podemos negligenciar o conhecimento científico enquanto forma já consagrada de cultuar e desenvolvimento de nossa sociedade. Contudo, segundo este autor urge a necessidade de contrabalançarmos esta forma de saber com os fatores próprios do chamado senso comum, a fim mesmo de permitir que deste saber desabrochem aqueles aspectos aclamados pela chamada filosofia intercultural, os quais não só admitem outros "logos" étnico-culturais, como também fomenta que devemos

R. Inter. Interdisc. INTERthesis, Florianópolis, v.11, n.2, p.37-54, Jul-Dez. 2014
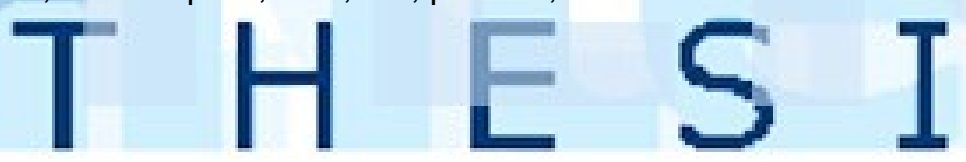
aprender com eles, somar com as diferenças. B. de Souza Santos não está sozinho nesta análise, e podemos brinda-la com o parecer de outros pensadores.

Para Morin (2003), o desenvolvimento da ciência moderna trouxe vantagens por um lado, porém desvantagens por outro. O homem recebe muitas informações e pouco conhecimento que se torna fracionado. A cultura científica separa as áreas do conhecimento e quando a percepção do todo enfraquece se perde o senso de responsabilidade. Com o novo pensamento científico essa visão está mudando.

A segunda revolução científica do século $X X$ pode contribuir, atualmente, para formar uma cabeça bem-feita. Essa revolução, iniciada em várias frentes dos anos 60, gera grandes desdobramentos que levam a ligar, contextualizar e globalizar os saberes até então fragmentados e compartimentados (MORIN, 2003, p. 26).

Nesse contexto é imprescindível mudar a forma de pensamento dos indivíduos, diante da sociedade, das culturas, do senso de "humanidade", dando abertura para refletir sobre a própria vida, levando a uma construção mais ampla do conhecimento. "Os indivíduos humanos produzem a sociedade nas interações e pelas interações, mas a sociedade, à medida que emerge, produz a humanidade desses indivíduos, fornecendo-Ihes a linguagem e a cultura" (MORIN, 2003, p. 95).

O paradigma emergente caminha no sentido da "revolução" aludida por Morin, conspirando em várias frentes para uma derradeira mudança de concepção no fazer da ciência e no desenvolvimento de uma cosmovisão mais antenada com as transformações que assistimos nos dias atuais. O desenvolvimento científico moderno resultou em mera acumulação, o qual constitui num conhecimento disciplinar, "sendo um conhecimento disciplinar, tende a ser um conhecimento disciplinado" (SANTOS, B. 2008, p. 74). Em consequência disso surgem obstáculos para o estudo de tais acumulações. "É hoje reconhecido que a excessiva parcelização e disciplinarização do saber científico faz do cientista um ignorante especializado e que isso acarreta efeitos negativos" (SANTOS, B. 2008, p. 74). O paradigma emergente constitui num repensar a ciência, propõe uma fragmentação temática e não disciplinar, onde os conhecimentos progridem ao encontro uns dos outros, surgindo um novo fazer científico.

O conhecimento do paradigma emergente tende assim a ser um conhecimento não dualista, um conhecimento que se funde na superação das distinções tão familiares e óbvias que até há pouco considerávamos insubstituíveis (SANTOS, B. 2008, p. 64).

R. Inter. Interdisc. INTERthesis, Florianópolis, v.11, n.2, p.37-54, Jul-Dez. 2014
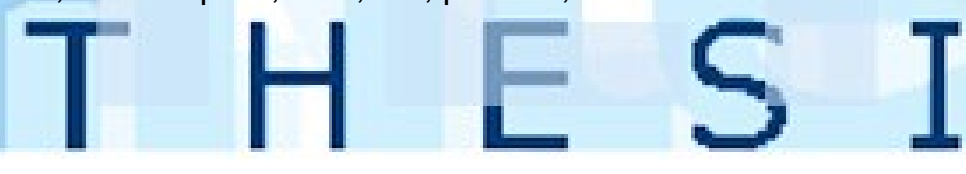
No novo paradigma o conhecimento científico e o senso comum se fundem, restabelecendo a esquecida capacidade de contemplação das coisas. B. Santos (2008) acredita ser iminente a conciliação entre sujeito epistêmico e sujeito empírico, indo mais além, a fusão entre sujeito e objeto. Essa junção constituiria num avanço importante na prática da pesquisa científica.

Apesar de vivermos no século XXI, ainda permanecemos presos em conceitos dominantes. Somos protagonistas da revolução científica iniciada no século XVII, um conhecimento baseado em uma ordem mecanizada e estável de mundo. "As leis da ciência moderna são um tipo de causa formal que privilegia o como funciona das coisas em detrimento de qual o agente ou qual o fim das coisas. É por esta via que o conhecimento científico rompe com o conhecimento do senso comum" (SANTOS, B. 2008, p. 30). As leis rígidas do paradigma dominante acabam interferindo na interpretação e relação dos fenômenos sociais, pois estes possuem caráter subjetivo. O racionalismo moderno foi marcado por uma confiança de que o método atribuiria ao homem pleno conhecimento e, portanto, capaz de atribuir-lhe a expansão de verdades, o que acabou conduzindo a um propósito de dominação, servindo de salvaguarda para o sistema capitalista.

No plano social, é esse também o horizonte cognitivo mais adequado aos interesses da burguesia ascendente que via na sociedade que começava a dominar o estádio final da evolução da humanidade (o estado positivo de Comte; a sociedade industrial de Spencer; a solidariedade orgânica de Durkhein). Daí que o prestígio de Newton e das leis simples a que reduzia toda a complexidade da ordem cósmica tenham convertido a ciência moderna no modelo de racionalidade hegemônica que a pouco e pouco transbordou do estudo da natureza para o estudo da sociedade. (SANTOS, B. 2008, p. 31-32).

De acordo com B. Santos (2008), é inviável compatibilizar os mesmos critérios das ciências naturais para as sociais, visto que nas ciências sociais não podemos fazer previsões confiáveis, os grupos sociais possuem suas próprias formas de viver, também o ser humano muda seu comportamento em função do conhecimento que adquire ao longo de sua existência. "Os fenômenos sociais são de natureza subjectiva e como tal não se deixam captar pela objectividade do comportamento". (SANTOS, B. 2008, p. 36).

É precisamente nesse contexto que se denuncia a má interpretação das culturas indígenas, posto que rica e plena de conhecimento empírico, em formas de tradição que valorizam em muito o senso comum, o que a torna invariavelmente

R. Inter. Interdisc. INTERthesis, Florianópolis, v.11, n.2, p.37-54, Jul-Dez. 2014
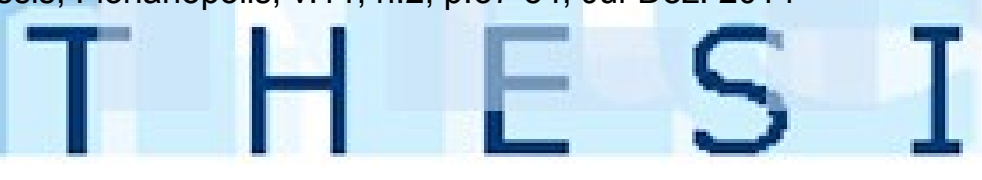
marginalizada frente ao logos do paradigma dominante. Com efeito, as diferenças das etnias indígenas em relação a nossa são tão pronunciadas que algumas peculiaridades destas culturas chegam mesmo a desafiar a consistência de nossas racionalidades tal como consagradas no paradigma dominante ocidental. Podemos deduzir que existam indeléveis limitações em quaisquer tentativas de interpretações de seus aspectos mais profundos a partir da ótica do paradigma dominante. Não raro, chegam a considerar os índios como insanos, primitivos ou simplesmente desprovidos de uma racionalidade mais bem elaborada. A filosofia intercultural vem para desmistificar tais estigmas. Ela nos ajuda a desvelar o logos oculto de culturas que apenas "pensam" e "fazem" diferente de nós.

\title{
3 DO QUE TRATA A FILOSOFIA INTERCULTURAL?
}

Nas palavras de um dos principais expoentes desta filosofia:

\begin{abstract}
tratar-se-ia [...] de não converter nossa própria maneira de pensar no lugar do encontro com o outro; isto é, não fazer do nosso mundo categorial o centro a partir do qual nós "compreendemos" o outro, no sentido de defini-lo e determina-lo à luz de nosso horizonte de compreensão. Esse "entender" assimila e incorpora por redução, mas não se cumpre como conhecimento que re-conhece no outro uma fonte de sentido de igual originalidade e dignidade. (FORNET-BETANCOURT, 1994, p. 18)
\end{abstract}

No contexto da filosofia intercultural podemos articular saberes sem descaracterizar a individualidade de cada sujeito ou de cada etnia. A filosofia intercultural propõe um ponto de partida para reflexão, afastando as convenções locais impostas pelas culturas dominantes. "Filosofia es un nombre particular que recibe una profunda experiência humana común a todas las culturas y épocas". (SANTOS, J. 2010, p. 90) ${ }^{5}$. Não existe exclusão da cultura do outro e sim uma nova forma de diálogo, visa acabar com o etnocentrismo e abre espaço a legitimar, valorizando a experiência de todos os grupos culturais, respeitando diferenças étnicas, maneiras de pensar e atuar.

Se trata pues, de inaugurar nuevas relaciones entre sujetos y de elaborar una reflexión sobre la nueva dimensión del discurso filosófico en la creación del diálogo intercultural, orientado hacia nuevos espacios abiertos y públicos para mundos y realidades mejores, en el intento de brindar una mejor

5 "Filosofia é um nome especial para uma experiência humana profunda comum a todas as culturas e épocas”. (SANTOS, J. 2010, tradução nossa).

R. Inter. Interdisc. INTERthesis, Florianópolis, v.11, n.2, p.37-54, Jul-Dez. 2014
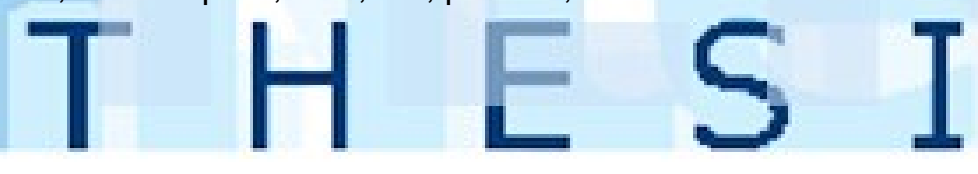
comunicación, tolerancia y derechos humanos entre las personas. (FERNÁNDEZ, 2004, p. 11). ${ }^{6}$

Essas diferenças podem ser valorizadas de forma interativa. Não compete apenas em reconhecer o outro, é imprescindível estabelecer uma relação de respeito dentro e fora do contexto da existência compartilhada, com o compromisso de condicionar o outro em sua liberdade para manifestar suas potencialidades.

\begin{abstract}
Se busca el reconocimiento de la alteridade desde una práctica histórica que de cuenta de las verdades particulares de cada universo cultural y que a su vez se puedan legitimar las subjetividades que dan origen al encuentro entre culturas. El entendimiento con cualquier otra cultura, para que se de un proceso comunicacional, parte de la aceptación de las proposicioneslenguaje y símbolos de todas las culturas. (FERNÁNDEZ, 2004, p. 13). ${ }^{7}$
\end{abstract}

Nesse contexto a filosofia intercultural propõe uma nova forma de repensar a diversidade cultural, em que os grupos possam conviver em um contexto de troca de experiências por eles vividas.

La filosofia intercultural tiene como deber principal transformar el mundo, cambiando las condiciones de la existência humana, sintetizando la transformación hermenêutica y epistemológica en una antropológica, no basta una revolución económica, social, ni política, sino antropológica. (FERNÁNDEZ, 2004, p. 18). ${ }^{8}$

Vivemos em um país com uma diversidade cultural significativa, mesmo a nível local, esse multiculturalismo é amplamente perceptível. Os povos indígenas contribuem para essa riqueza sociocultural. Para uma convivência harmônica, é imprescindível modificar o comportamento e as relações sociais. A filosofia intercultural pode contribuir no processo reflexivo sobre a diversidade presente na comunidade indígena. A articulação de diferentes saberes, ajuda a formular a noção de respeito pelas particularidades de cada sujeito ou grupo, ou seja, entender a manifestação simultânea de diversas culturas. "Sua atenção centra-se melhor na

\footnotetext{
${ }^{6}$ Trata-se, pois, de inaugurar novas relações entre sujeitos e de elaborar uma reflexão sobre a nova dimensão do discurso filosófico na criação do diálogo intercultural, orientado para novos espaços abertos e públicos, para mundos e realidades melhores, no intuito de ofertar melhor comunicação, tolerância e direitos humanos entre as pessoas. (FERNANDEZ, 2004, tradução nossa).

${ }^{7}$ Busca-se o reconhecimento da alteridade desde uma prática histórica que dê conta das verdades particulares de cada universo cultural e que, por sua vez, possa legitimar as subjetividades que dão origem ao encontro entre culturas. $\mathrm{O}$ entendimento com qualquer outra cultura, para que se dê um processo comunicacional, parte da aceitação de proposições da linguagem e os símbolos de todas as culturas. (FERNANDEZ, 2004, tradução nossa).
}

${ }^{8} \mathrm{~A}$ filosofia intercultural tem como dever principal transformar o mundo, mudando as condições da existência humana, sintetizando a condição hermenêutica e epistemológica em uma antropológica, não basta uma revolução econômica, social, nem política, mas antropológica. (FERNANDEZ, 2004, tradução. nossa).

R. Inter. Interdisc. INTERthesis, Florianópolis, v.11, n.2, p.37-54, Jul-Dez. 2014
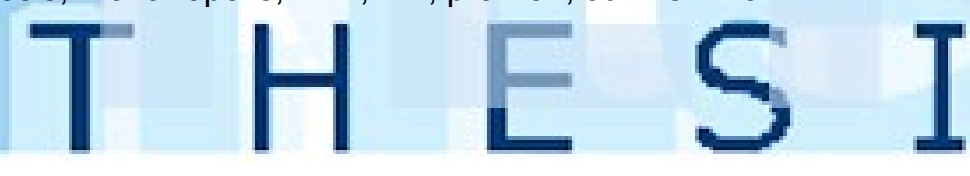
busca de pistas culturais que permitam a manifestação polifônica daquilo que chamamos filosofia desde o multiverso das culturas." (SIDEKUM, S/A, p.5). Para conviver de forma harmoniosa com as diferenças, o indivíduo precisa reconhecer primeiramente as origens e significações dos componentes de determinadas culturas e suas particularidades.

Não obstante a "polifonia" de nossos contextos geográficos, étnicos e culturais, percebe-se ainda o "ranço" de perspectivas que se apegam ao "paradigma dominante", com o predomínio não somente de certas formas de se construir o conhecimento, mas também de formas de se entender o mundo e as relações das pessoas entre elas mesmas e com a natureza. Tudo isto, como vimos, desemboca invariavelmente em algum desenho de cosmovisão, ou seja, um produto social e histórico carregado de conceitos difíceis de mudar, implicando em hábitos culturais arraigados que podem "cegar" a visão para outros logos que não o nosso próprio modo de interpretar a natureza e o homem. A filosofia intercultural é uma corrente de reflexão que pode, portanto, enfraquecer a resistência de formas de pensamento da cultura dominante, onde predomina o etnocentrismo. "Desde la perspectiva intercultural la visualizamos como una forma de interpretar el mundo que parte de princípios diferentes a los nuestros y que da como resultado una visión distinta de lo que nos rodea". (SANTOS, J. 2010, p. 94) ${ }^{9}$. A proposta dessa nova forma de interpretar um povo, uma cultura, requer diferentes formas de pensar, de criar e recriar.

No paradigma emergente, onde o conhecimento científico se funde com o senso comum, podemos interpretar que o saber cotidiano do indivíduo se torna valorizado. Assim, a filosofia intercultural vai ao encontro do paradigma emergente, restabelecendo e refletindo sobre as práticas culturais específicas de um povo. Essa forma de pensar implica na preservação e principalmente no resgate da racionalidade de culturas marginais, combatendo o prejuízo de toda sorte de atitudes que não enxerguem o valor intrínseco de culturas autóctones. Como afirma FornetBetancourt (1993), "não há, portanto, valores absolutos, de validez supra-histórica. O que há, são valores históricos, isto é, valores de validez relativa, valores

\footnotetext{
${ }^{9} \mathrm{~A}$ partir da perspectiva intercultural visualizarmos uma forma de interpretar o mundo partindo dos princípios diferentes dos nossos e que da como resultado uma visão diferente ao que nos rodeia. (SANTOS, J. 2010, tradução nossa).
}

R. Inter. Interdisc. INTERthesis, Florianópolis, v.11, n.2, p.37-54, Jul-Dez. 2014 
dependentes das valorações humanas e da perpétua transmutação que estas sofrem" (p. 108).

\section{COMUNIDADE RIO D'AREIA: POSSIBILIDADES ABERTAS POR UM DIÁLOGO INTERCULTURAL}

Comunidade, segundo o dicionário Aurélio, implica "qualquer grupo social cujos membros habitam uma região determinada, têm um mesmo governo e estão irmanados por uma mesma herança cultural e histórica”. (FERREIRA, 2009, p. 513), sendo a convivência em grupo, segundo crenças, formas de pensar, costumes, interesses, conhecimentos e princípios comuns. Ao conjunto dessas características chamamos de cultura, com a qual os grupos convivem em um contexto de troca de experiências por eles vividas. Dessa forma, ao participar de um determinado grupo social, o ser humano está se afirmando como indivíduo ao passo que reafirma seus interesses pessoais.

A comunidade é uma unidade estruturada, organizada, de grupos, dispondo de uma hierarquia homogênea de valores e à qual o indivíduo pertence necessariamente; essa necessidade pode decorrer do fato de se "estar lançado" nela ao nascer, [...] ou de uma escolha relativamente autônoma do indivíduo já desenvolvido. (HELLER, 1970, p. 70-71).

Assim, pensando da perspectiva comunitária, o próprio sentido de individualidade é dependente do conjunto de valores e regras sociais compartilhados pela coletividade na qual esta individualidade se insere. As inter-relações destas individualidades contribuem para a formação do ambiente social, uma vez que as pessoas tendem a se agrupar por características comuns. Compreender os aspectos que se encontram imersos na vida da comunidade, a partir da cultura existente na mesma, a forma de produzir sua existência, é imprescindível para uma convivência mais humana.

A comunidade Indígena Rio D'areia apresenta as mais diversas relações com outras comunidades e etnias, sofrendo influência da nossa sociedade. Dentro da aldeia instalou-se uma igreja evangélica "Assembleia de Deus". Com a intenção de atrair mais fiéis, os cânticos foram traduzidos para o guarani. A comunidade fica dividida, alguns participam da igreja, e parte da comunidade preserva a Opy (casa de reza Guarani) - é um lugar sagrado onde se reúnem para aconselhamento e os mais jovens e as crianças escutam conselhos dos mais velhos que são respeitados e considerados sábios no ciclo social. "Os mais velhos ensinam entre conselhos e as

R. Inter. Interdisc. INTERthesis, Florianópolis, v.11, n.2, p.37-54, Jul-Dez. 2014
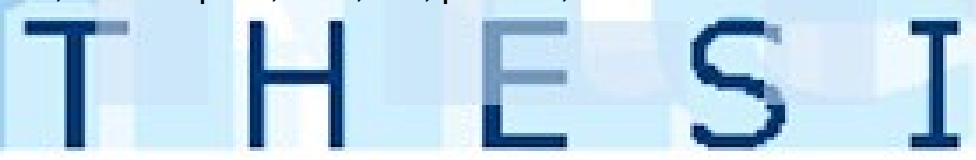
suas práticas. Nos trabalhos mostravam para seus filhos como eles faziam e ensinavam também através de informação oral”. (SEED, 2012, p. 85). A Opy também é usada para os rituais religiosos, a casa de reza é um lugar para "falar com Deus" Nhanderu. Os encontros para os rituais religiosos seguem uma tradição da cultura guarani.

A influência tecnológica, como: rádio, televisão e internet, está presente na comunidade, trazendo novos padrões de comportamento, influenciando o modo de viver do indígena. Quando nos defrontamos com tal estado de coisas, logo fica evidente o descompasso que existe entre estas culturas. Os índios recebem uma carga de influência bem maior do que a carga que recebe nossa cultura. Neste descompasso, há um prejuízo para ambas: fazendo uma metáfora com elementos da natureza, podemos dizer que os índios recebem nossas influências como a enchente de um rio, atravessando-se impositivamente sobre o que estiver pela frente; por outro lado, nós, da cultura que nutriu o paradigma dominante, caímos em uma espécie de "vazio ancestral" pela simples negligência dos valores e da racionalidade de um povo que já estava aqui há milênios. Em suma, quando deixamos de contemplar a racionalidade típica de um povo que nos seja diferente, deixamos escorrer pelas mãos alguns tesouros que certamente nos farão falta em algum momento. Quando não há uma autêntica interculturalidade, todos saem perdendo. Há necessidade de compreender a ascendência desse povo, considerando aspectos históricos, linguísticos, sociais e culturais. Neste ínterim, a filosofia intercultural permite enxergá-los como legítimos, como produtores de culturas e saberes, evitando a imposição dos padrões da cultura dominante, porém dialogando com eles.

O momento atual convoca todos a adaptações nos mais diversos âmbitos, pois as tecnologias cada vez mais avançadas, se sobrepõem a todas as áreas de nossa sociedade. Esses avanços trazem vários benefícios. Entre outros, visa a melhoria da qualidade de vida e o desenvolvimento e convívio mais harmônicos do indivíduo na comunidade. "Se o conhecimento leva a alguma parte, é ao entendimento, à compreensão, e isto leva a uma ação harmônica e ajustada com os outros e o meio". (MATURANA, 2002, p.55). Por outro lado, essas transformações requerem inovações na forma de pensar, o qual deve contemplar o saber científico em comunhão com o senso comum.

R. Inter. Interdisc. INTERthesis, Florianópolis, v.11, n.2, p.37-54, Jul-Dez. 2014
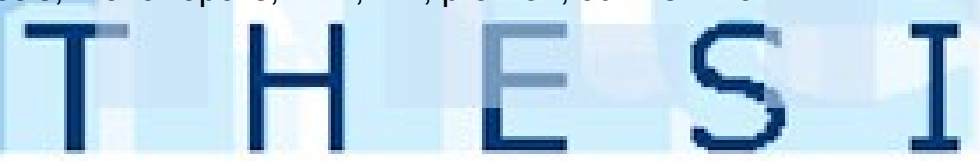
À luz da filosofia intercultural, podemos enxergar o outro sem ofender suas características. Basta que mudemos nossas formas de contemplação, de modo a interpretar mais acertadamente os momentos de seu cotidiano nos quais aspectos típicos de sua cultura estejam prevalecendo. Elencamos a seguir alguns momentos dentro da comunidade Rio D'Areia:

\section{O ATO FÚNEBRE}

Na Reserva indígena Guarani, alguns índios preservam os costumes dos antepassados. Ao falecer um índio, este é velado na casa de reza, o ocorrido é lamentado por todos, o pajé caminha de um lado até o outro discursando sobre o sucedido, fala sobre a vida do falecido, lembrando que todos devem refletir sobre a vida. O ritual de reza e cânticos segue onde todos participam. Ao terminar, o pajé toma a palavra prosseguindo o discurso, depois deixa livre pra quem quiser se pronunciar. O ritual fúnebre se estende noite afora. O corpo é enterrado no outro dia em uma cova funda. O ritual religioso é feito na casa de reza durante sete dias, no sétimo dia é feito um caixão levado na casa de reza e o ritual repetido como se o falecido estivesse presente. O caixão vazio é enterrado certificando assim o falecimento. $O$ respeito durante o velório é muito grande. Não existe conversa paralela, as meninas fazem chimarrão, que é servido pra todos os presentes. Mesmo com o cerimonial feito dentro do costume guarani, o caixão feito de madeira é influência da cultura do não-índio. Isto já revela certo sincretismo entre as culturas. "Antigamente indígenas que morriam eram enterrados dentro da urna. Mas agora os índios costumam usar caixões fabricados pelos brancos e feitos de madeira. Os indígenas têm feito de barro". (SEED, 2012, p. 51). Nesse contexto, a filosofia intercultural pode contribuir para refletirmos sobre a maneira como é conduzida o ato fúnebre desse povo. Podemos deduzir de seu ritual que o respeito aos mortos vai além da saudade de alguém que se foi. $O$ ato fúnebre convoca todos, em seus silêncios, a uma introspecção que faz refletir sobre a própria vida.

\section{A LEI E A ORDEM INDÍGENA}

Quando um indígena faz algo inconveniente que venha a impedir o andamento da ordem na comunidade, que desagrade a liderança "policial" da R. Inter. Interdisc. INTERthesis, Florianópolis, v.11, n.2, p.37-54, Jul-Dez. 2014

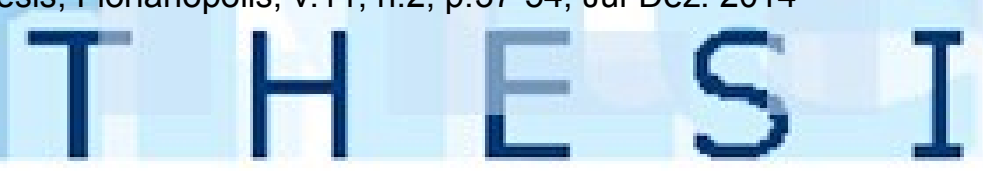


própria comunidade, que são nomeados pelo cacique ou decidido em reunião, é levado para "cadeia" (cubículo pequeno construído por eles) e deixado lá para que o preso possa refletir sobre seu erro. Um exemplo que pode terminar em cadeia é quando o indivíduo se embriaga e começa a brigar em casa. Se o cônjuge reclamar para o cacique, este dá ordens para prender. Numa situação presenciada na reserva um homem embriagado começou a quebrar os móveis, ao que sua esposa reclamou. O índio foi preso e no outro dia seu filho pequeno de três ou quatro anos foi levar alimento para o pai. Esta prática destoa bastante das que estamos acostumados em nossa cultura nas situações de visita a presidiários. Na ótica da tribo guarani, este costume é para que o errante reflita e, diante da pureza da criança, sinta vergonha do seu ato. Sabe-se que nosso sistema de encarceramento passa bem longe desta lógica presente na tribo. As "penas" indígenas são educativas e sempre oferecem chance de "cair" e se "levantar". Outra forma de punição é a pessoa que errou pagar em forma de "castigo" (como eles falam), que é roçar ou capinar o mato em determinado espaço da comunidade. O tamanho do local a ser limpo depende da infração cometida, sendo decidido em reunião da liderança. Esta forma de punição já lembra nossos presídios agrícolas ou mesmo as variadas formas de trabalho penal. O castigo é aplicado tanto para os homens como para as mulheres, não importa o gênero. Se errar o castigo é decidido conforme o ato. A liderança só interfere se tiver reclamação.

\section{DEUS ESTÁ CHORANDO...}

Numa situação ocorrida em março de 2008, a caminho da Reserva para efetuar a observação participante, chovia muito, e o carro tombou faltando aproximadamente um quilômetro da comunidade. Várias pessoas foram ajudar a tirar o carro, o qual estava suspenso em duas árvores, prestes a cair num precipício. O difícil acesso à Reserva exige o máximo de atenção. Inclusive o tratorista índio e as crianças indígenas, também foram socorrer, fato que é muito comum na cultura desta Reserva, pois as crianças participam ativamente nos afazeres dos adultos. Interessante notar, com este fato, que não há constrangimento entre crianças e adultos. Isto nos faz pensar sobre os tabus que nossa própria cultura enfrenta quando, em algumas famílias ou etnias, as crianças ou adolescentes são convocadas para auxiliar no trabalho dos adultos. O menino índio de doze anos

R. Inter. Interdisc. INTERthesis, Florianópolis, v.11, n.2, p.37-54, Jul-Dez. 2014
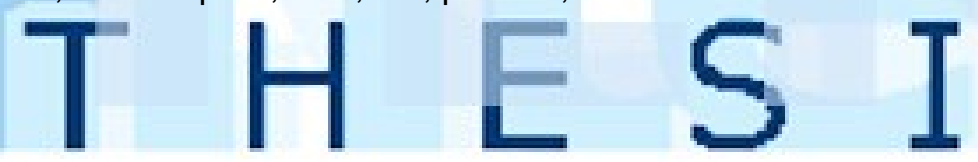
falou: "Deus não deixou que nada acontecesse com você, porque você não faz mal a ninguém". Após ajudar a engatar o carro sentou na grama, todo molhado ficou meditando, olhou para o céu e novamente se dirigiu a mim, com a expressão triste assim falou: "Deus está chorando... não sei por que". Na perspectiva do índio, os fenômenos da natureza são "animados", isto é, são encarados como se tivessem algum tipo de consciência e vontade próprias. Daí que esta e outras etnias indígenas têm muito a contribuir com nossas intermináveis discussões sobre ecologia e meio ambiente. A valorização da natureza, das florestas e de tudo que nelas existem são tradições sociais e formas de tipificar a tradição indígena.

Se fôssemos lançar um olhar etnocêntrico, típico do paradigma dominante, estranharíamos muito a racionalidade de alguns costumes como estes, e mais ainda outros que sequer foram citados. De uma perspectiva etnocêntrica, não são poucos os comentários que emitem juízo de valor sobre os costumes indígenas (ou mesmo de outras culturas), qualificando-os de menos desenvolvidos, grosseiros ou primitivos. A filosofia intercultural, reforçando a urgência de um paradigma emergente para o conhecimento, põe em cheque tais formas de reducionismo cultural, abrindo todo um campo de possibilidades para contemplarmos e aprendermos com as diferentes culturas. "La interculturalidad com base em el diálogo busca la interacción, tal como lo há expressado la racionalidade occidental". (FERNÁNDEZ, 2004, p. 22) ${ }^{10}$. Dentro desta perspectiva, podemos enxergar o outro, respeitando seus caracteres, e até mesmo aperfeiçoar nossos próprios costumes, aprendendo com eles, aprendendo com o "diferente".

\section{CONSIDERAÇÕES FINAIS}

Este trabalho e a pesquisa que envolveu permitiu estabelecer um vínculo entre a filosofia intercultural e a proposta do paradigma emergente, onde o senso comum, típico de tradições como a indígena, recebe um tratamento de respeito no que tange ao seu logos. Não foi o intuito aqui estender-se muito em exemplos do cotidiano indígena-guarani. Os exemplos acima se prestaram, a título de ilustração, para transmitir uma ideia inicial que permita outros trabalhos de pesquisa se desenvolverem a partir daqui.

\footnotetext{
${ }^{10} \mathrm{~A}$ interculturalidade com base no diálogo busca a interação, tal como não existe expressado na racionalidade ocidental. (FERNÁNDEZ, 2004, tradução nossa).
}

R. Inter. Interdisc. INTERthesis, Florianópolis, v.11, n.2, p.37-54, Jul-Dez. 2014
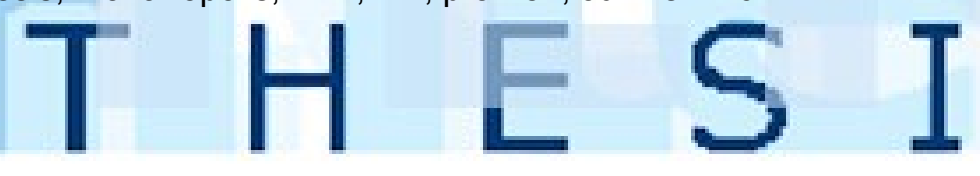
Vimos que a filosofia intercultural, ainda incipiente, visa criar as condições para o estabelecimento de uma relação de respeito entre as diferentes culturas, enxergando a todas como legítimas, cada qual possuidora de um logos que se constituiu ao longo de sua história. Ela permite, então, entender o lugar do outro como um conjunto próprio de relações simbólicas construídas nas suas diversas maneiras de se expressão. Ela vem reiterar o preenchimento de uma lacuna já aludida momentos atrás: que a cultura do não-índio também seja passível de sofrer influência da cultura indígena, visto que esta possui características muito peculiares, podendo contribuir consideravelmente para 0 crescimento e expansão de conhecimento de todos aqueles que se predispuserem a observá-la sem as amarras preconceituosas típicas de enfoques etnocêntricos.

Guiados pelo farol de um paradigma emergente, pode ser que o momento seja maduro para começarmos relativizando todas as culturas, seus valores e racionalidades. O foco agora não é mais "quem tem a razão", tão alardeado nos ideais iluministas do século XVIII. O foco que talvez esteja mais sintonizado com a emergência de um novo paradigma é o intercâmbio de razões, a troca frutífera entre racionalidades oriundas de histórias tão ricas e tão díspares, entre culturas que podem aprender umas com as outras, onde haja um diálogo recíproco. Quando experimentamos as coisas desta outra perspectiva, passamos a nutrir tacitamente um sentido de pertencimento intercultural, o que conduz para uma via de mão dupla: se por um lado isto nos habilita a valorizar os costumes e a racionalidade do outro, na via inversa somos alvos da mesma "curiosidade saudável" deles para com a nossa cultura e modo de pensar.

A experiência obtida com a observação participante na Reserva indígena faznos perceber que no lugar de enxergar um hiato intransponível entre as diferentes culturas, é possível contemplar a possibilidade de um encontro sui generis entre elas, capaz de promover aprendizados e desenvolvimentos mútuos. Com efeito, não são apenas as culturas indígenas que se beneficiam deste novo paradigma nos enfoques, pois o ganho se estabelece para todas as culturas que estejam em relação, onde a quebra de barreiras interculturais acaba atuando como a quebra de preconceitos.

R. Inter. Interdisc. INTERthesis, Florianópolis, v.11, n.2, p.37-54, Jul-Dez. 2014
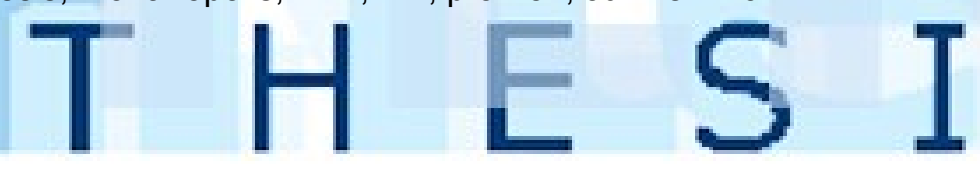


\title{
INTERCULTURAL PHILOSOPHY AND EMERGING PARADIGM: A NEW APPROACH TO THE "REASONS" OF A DIFFERENT CULTURE
}

\begin{abstract}
This research begins with the questioning of a certain paradigmatic crisis that, according to some authors, is not restricted to the scientific modus faciendi, but also reaches knowledge itself, considered under a broader perspective and applied to all our values and relationship among men, nature and society. It's worth mentioning the crisis that is known as "dominant paradigm", by which there is an urgent need for a new scientific practice and a new form of knowledge appropriation, one in which the common sense is rescued and receives proper value. This is the proposal of the so called "emerging paradigm" which we believe, paves the way for the heterodoxy of proposals, such as the Intercultural Philosophy, to find conducive soil in the construction of alternative ways, to embrace indigenous knowledge and cultures. Some epistemological aspects that make up the Intercultural Philosophy are described, in particular, its negative view on ethnocentrism. It is argued that this new form of making philosophy meets the requirements of an emerging paradigm; in that it does not favor this or that logos as the "absolute and universal reason", but allows the expression of other forms of rationality that often clash the standards of what is considered "conventional", as in the case of indigenous cultures. All these paradigmatic and intercultural principals find echo in the interpretation of some forms of rationality unique to the Rio D'Areia Indian Reserve, located in the municipality of Inácio Martins, Paraná, whose data was collected through participant observation.
\end{abstract}

Keywords: Paradigm. Rationality. Ethnocentrism. Intercultural philosophy. Indigenous community.

\section{FILOSOFÍA INTERCULTURAL Y PARADIGMA EMERGENTE: UN NUEVO ENFOQUE PARA LAS "RAZONES" DE UNA CULTURA DIFERENTE}

\section{RESUMEN}

Se inicia este trabajo con una problematización de cierta crisis paradigmática que de acuerdo con algunos autores, no se restringe al modus faciendi científico, que atañe también el propio conocimiento, considerándolo bajo una perspectiva más amplia, aplicándose a todo el conjunto de nuestros valores y relaciones entre hombre, naturaleza y sociedad. Cabe destacar la crisis de lo que se denomina como el "paradigma dominante", a través del cual urge la necesidad de un nuevo hacer científico y una nueva forma de apropiación del conocimiento, en que el sentido común es rescatado y recibe la debida valoración. Esta es la propuesta del así llamado "paradigma emergente" que según entendemos, prepara el camino para que la heterodoxia de propuestas, como la de la Filosofía Intercultural, encuentren suelo propicio en la construcción de formas alternativas para encararse culturas y saberes autóctonos. Se describen algunos aspectos epistemológicos que componen la Filosofía Intercultural, en especial su negativa con respecto al etnocentrismo. Se pretende argumentar que esta nueva forma de filosofar atiende a los requisitos de un paradigma emergente, en la medida en que no privilegia este o aquel logos como la "razón absoluta y universal", sino que permite la expresión de otras formas de racionalidad que, no pocas veces, confrontan con los patrones de lo que se considera "convencional", como es el caso de las culturas indígenas. El conjunto de estos principios paradigmáticos e interculturales encuentran eco en la interpretación de algunas formas de racionalidad típicas de la Reserva Indígena Río D' Areia, situada en el municipio de Inácio Martins, en Paraná, cuya recolección de datos fue realizada a través de la observación participante.

Palabras clave: Paradigma. Racionalidad. Etnocentrismo. Filosofía intercultural. Comunidad indígena.

R. Inter. Interdisc. INTERthesis, Florianópolis, v.11, n.2, p.37-54, Jul-Dez. 2014
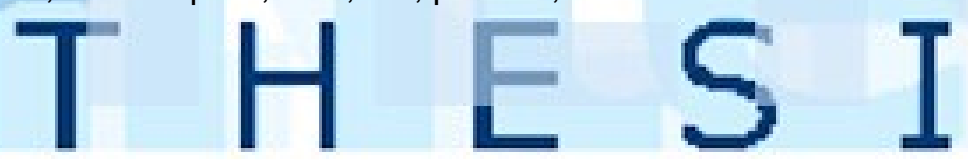


\section{REFERÊNCIAS}

FERREIRA, A. B. H. Novo dicionário Aurélio da língua portuguesa. 4. ed. Curitiba: Positivo, 2009.

FERNÁNDEZ, D. G.; FERNÁNDEZ, A. B. M. Raúl Fornet-Betancourt: diálogo y filosofía intercultural. Universidad Nacional Experimental Rafael María Baralt Universidad del Zulia. Frónesis: Recibido: 16-04-2004. Aceptado: 09-11-2004 Vol. 11, No. 3, 2004: 9-39.

BETANCOURT, R. F. Problemas atuais da filosofia na Hispano-América. São Leopoldo, RS: Unisinos, 1993.

BETANCOURT, R. F. Questões de método para uma filosofia intercultural a partir da Ibero-América. São Leopoldo, RS: Unisinos, 1994.

HELLER, Agnes, Indivíduo e Comunidade. São Paulo: Paz e Terra, 2004.

KUHN, T. S. A estrutura das revoluções científicas. São Paulo: Perspectiva,1978.

MATURANA, R.. H. Emoções e linguagem na educação e na política. Belo Horizonte: Ed UFMG, 1998.

MORIN, E. A cabeça bem feita. 8 ed. Rio de Janeiro: Bertrand Brasil, 2003.

PERUZZO, C. Da observação participante à pesquisa-ação em comunicação: pressupostos epistemiológicos e metodológicos. In: INTERCOM - Sociedade Brasileira de Estudos Interdisciplinares da Comunicação. XXVI Congresso Brasileiro de Ciências da Comunicação - BH/MG - 2 a 6 Set 2003.

SANTOS, B. S. Um discurso sobre a ciência. 5. ed. São Paulo: Cortez, 2008.

SANTOS, J. ¿Filosofías en la aldea multiétnica?. Enfoques, Libertador San Martín, v. 22, n. 2, dic. 2010. Disponible en <

http://www.scielo.org.ar/scielo.php?script=sci arttext\&pid=S1669-

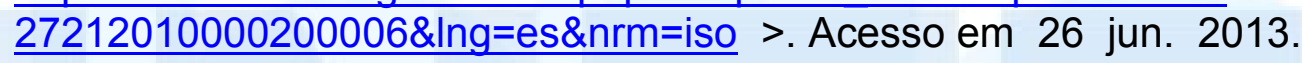

SEED, Secretaria de Estado da Educação. Ler, Escrever e se Guarani no Paraná. Fale - Faculdade de letras/UFMG, Litaraterras. 2012. 
SIDEKUM, A. Desafios para a filosofia intercultural: Cultura e poder. Editora Unijuí, 2003.Disponível em:

$<$ http://www.corredordelasideas.org/docs/set 04/antonio sidekum.doc $>$ Acesso em abr 2013.

Artigo:

Recebido em Fevereiro de 2014

Aceito em Julho de 2014

R. Inter. Interdisc. INTERthesis, Florianópolis, v.11, n.2, p.37-54, Jul-Dez. 2014
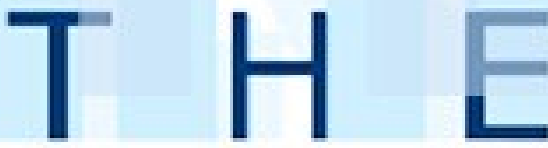